Case Report

\title{
Immediate Complete Overdenture - A case report
}

\author{
Ali Surahman Fatahillah, Michael Josef Kridanto Kamadjaja, Harry Laksono \\ Department of Prosthodontics Faculty of Dental Medicine \\ Universitas Airlangga \\ Surabaya - Indonesia
}

\begin{abstract}
Background: Edentulousness resulting from extraction of teeth often leads to psychological problem and social isolation of the patient. The patient has to adapt to the situation with respect to speech, chewing, swallowing, and so forth. A smooth transition from dentulousness to edentulousness is the result of immediate over denture with a few retained teeth. Purpose: to report overdenture prevents alveolar ridge bone absorption, stabilizes a denture, and makes the typical sensory function to be looked closer to natural teeth. Case: A 79year-old female complaint of missing multiple teeth and desire to replace them. Extraoral examination and temporomandibular joint movement were normal. Five teeth $(12,11,21,22,34)$ exhibited grade II mobility with diagnosis apical chronic periodontitis. Radiographic examination is an overview of diffuse radiolucent on the apical on the teeth 17,13,12,11,21,22,34. Case Management: First, make a diagnostic impressions of the maxillary and mandibular with irreversible hydrocolloid then poured in dental stone. After that, the final impressions were taken and poured in dental stone, casts mounted on articulators. Bite registration was done after using bite rim and bite registration material. The next step is setting up the artificial teeth then tried to the patient. Five teeth $(12,11,21,22,34)$ were trimmed from the casts on the functional model. The patients tooth 12 , 11,21,22 and 34 were reduced to a dome shape only $2 \mathrm{~mm}$ above gingival margin then restored with GIC on the surface. The denture was then placed immediately after reduced. Discussion: The selected abutments teeth were reduced to a dome shape only $2 \mathrm{~mm}$ above gingival margin. This will create adequate space for the overlying artificial denture tooth and denture base. Also, it reduces the lateral stresses and lever action of the tooth. The retained tooth roots, used for overdenture, transfers occlusal forces to the alveolar bone through the periodontal ligament and maintain alveolar ridge morphology. Conclusion: Overdenture can be used to prevents alveolar ridge bone absorption, stabilizes a denture, and makes the typical sensory function to be looked closer to natural teeth.
\end{abstract}

Keywords: Immediate, Overdenture, Magnet

Correspondence: Michael Josef Kridanto Kamadjaja, Department of Prosthodontics, Faculty of Dental Medicine, Universitas Airlangga, Jl. Prof. Dr. Moestopo No. 47 Surabaya 60132 - Indonesia, Phone: +62315030255 Email: michael-j-k-k@fkg.unair.ac.id

\section{INTRODUCTION}

Extraction of the last remaining teeth and replace with complete dentures has many consequences $^{1}$. The patient has to adapt to the situation with respect to speech, chewing, swallowing, and so forth ${ }^{2,3}$. Edentulousness resulting from extraction of teeth often leads to psychological problem and social isolation of the patient. ${ }^{4}$ The focus of dentistry is on preservation of teeth and other oral structures rather than focus on restoring what is lost. Preserving alveolar ridge integrity and maintaining the proprioceptive ability of the periodontium is a requirement for overdenture. ${ }^{5}$ A smooth transition from dentulousness to edentulousness is the result of immediate overdenture with a few retained teeth. ${ }^{6}$ To make a gradual dentition to complete dentures possible, overdenture therapy is recommended by prosthodontists. The purpose of this case was to report overdenture prevents alveolar ridge bone absorption, stabilizes a denture, and makes the typical sensory function to be looked closer to natural teeth

\section{CASE}

A 79-year-old female patient came to Universitas Airlangga Dental Hospital with the complaint of missing multiple teeth and desire to replace them. Patient still use the old denture but there was a discomfort with the old one. She gave a history of loss of teeth in the last 1 year and had pain and difficulty in chewing and desired to have dentures as soon as possible. She was apprehensive about extracting all the teeth. 


\section{Indonesian Journal of Dental Medicine}

Volume 1 Issue 1 2018; 31-34

Extraoral examination and temporomandibular joint movement were normal. Intraoral examination revealed upper and lower partially edentulous arches. The profile of the patient showed in Figure 1. Five teeth $(12,11,21,22,34)$ exhibited grade II mobility with diagnosis apical chronic periodontitis. The intra oral view showed in Figure 2 while the view of the old denture showed in Figure 3. Radiographic examination is an overview of diffuse radiolucent on the apical on the teeth $17,13,12,11,21,22,34$. Treatment planned was an immediate overdenture after intentional root canal treatment of the retained teeth (Figure 4).

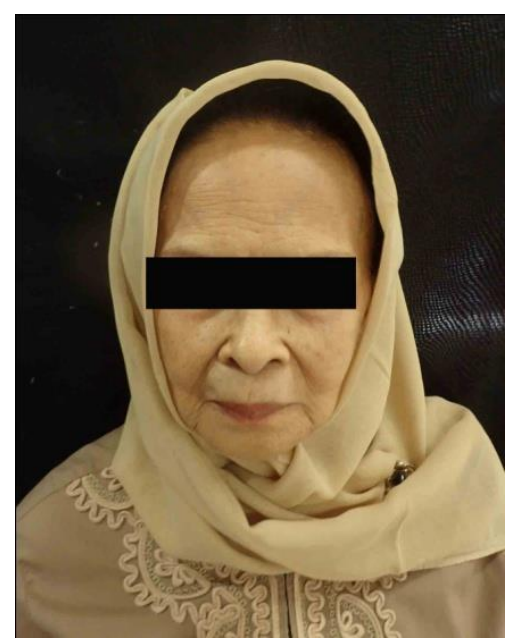

Figure 1. Patient Profile

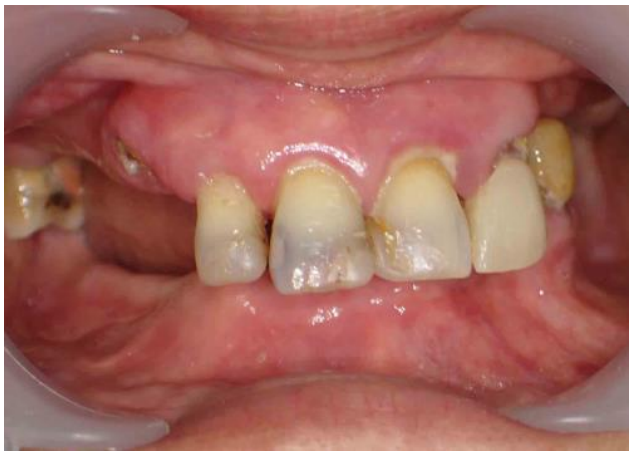

Figure 2. Preoperative Intraoral view

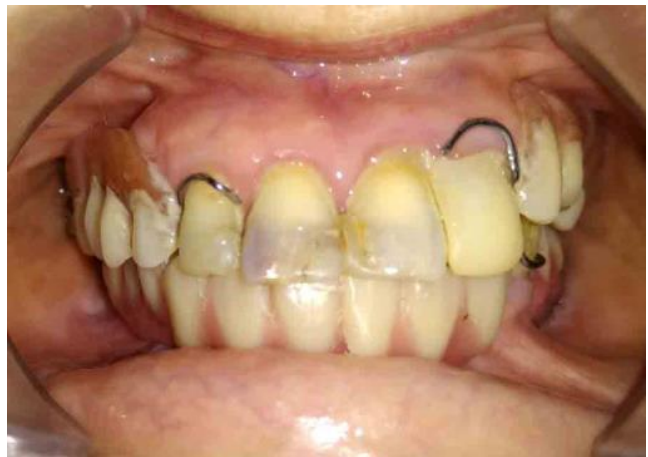

Figure.3 Preoperative Intraoral view with old partial denture

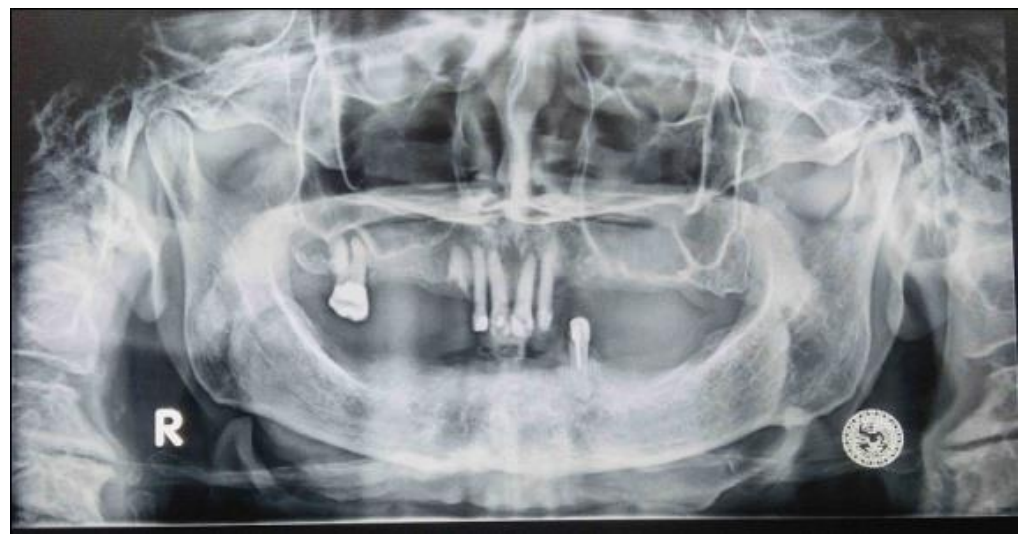

Figure 4. Radiographic examination is an overview of diffuse radiolucent on the apical on the teeth $17,13,12,11,21,22,34$ 


\section{CASE MANAGEMENT}

The first step of making immediate overdenture was making diagnostic impressions of the maxillary and mandibular arches and produced with irreversible hydrocolloid. The impressions were poured in dental stone and casts obtained. These diagnostic casts were used to fabricate an individual tray to final impression. After that, the final impressions were taken and poured in dental stone, casts mounted on articulators. Bite registration was done after using bite rim and bite registration material.

The next step on immediate complete overdenture fabricated by setting up the artificial teeth and then try in. Anterior Teeth which exhibited grade II mobility (12, 11, 21,22 and 34) were trimmed from the casts on the functional

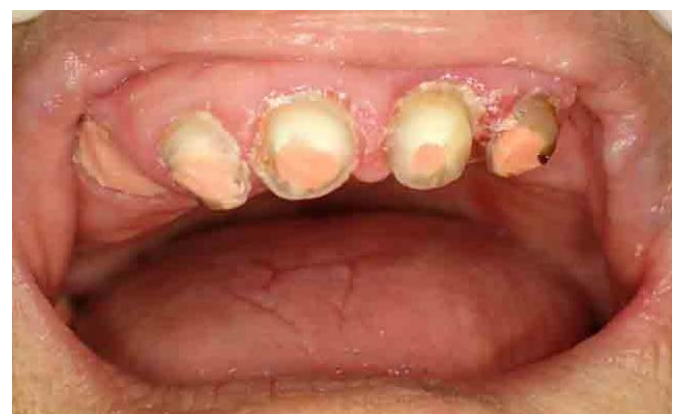

Figure 5. the tooth $12,11,21,22$ and 34 were reduced to a dome shape and restored with GIC model and all of the teeth were set in to the final cast. After the complete denture had been fabricated completely, the patients tooth 12,11 , 21,22 and 34 were reduced to a dome shape only $2 \mathrm{~mm}$ above gingival margin then restored with GIC on the surface (figure 5). The denture was then placed immediately after reduced (figure 6 and figure 7).

Patient was asked to wear the denture for the first 24 hours and was recalled the next day. Instruction regarding eating, speaking, denture cleanliness were given to patient. Patient was also explained about the possibility to reline or remake the denture later. Finally, at the recall visit fluoride application of abutment teeth was done to minimize the risk caries in these teeth.

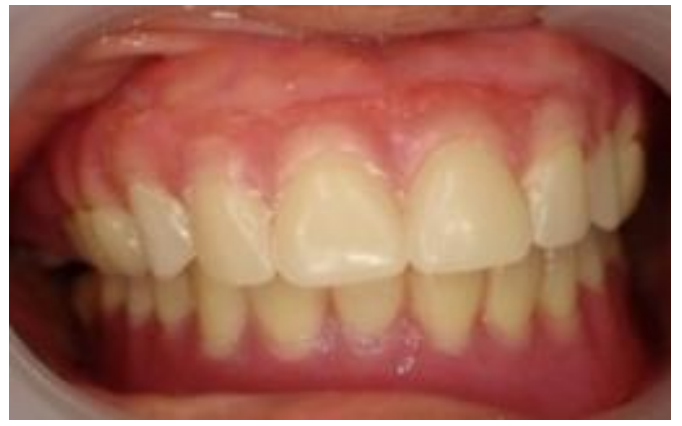

Figure 6. Post-operative Intraoral view

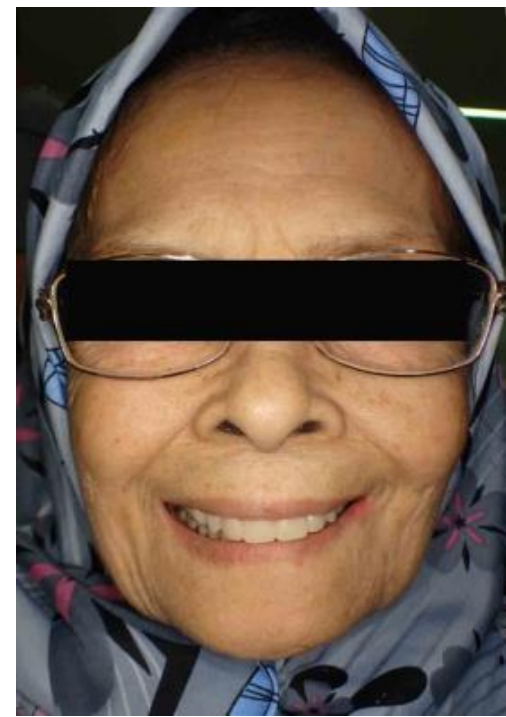

Figure 7. Profile picture after insertion Immediate Complete Overdenture

\section{DISCUSSION}

Patients who are about to lose all their natural teeth in one or both jaws may create a dilemma for themselves and their dentists. Before prosthetic impressions can be attempted on a reasonably stable residual ridge, a conventional complete denture is required a significant post extraction waiting period. The days of leading patient must go without teeth are leading to functional difficulties and social indignity before 
receiving the denture. The complete immediate overdenture offers a solution to this problem because it is constructed before the natural teeth are reduced and placed immediately afterward giving patient security and confidence. ${ }^{7}$

Retaining roots beneath denture aid in preservation of proprioception and reduce bone resorption. By retaining the mandibular canines in the use of an overdenture, the resorption of the alveolar bone surrounding these teeth was shown to be reduced by eight times between the canines, and it also preserved in both height and width posterior to the canines.

In the present case, the selected abutments teeth were reduced to a dome shape only $2 \mathrm{~mm}$ above gingival margin. The reduction in crown height for overdenture has several advantages. For example, it creates adequate space for the overlying artificial denture tooth and denture base. Also, it reduces the lateral stresses and lever action of the tooth The retained tooth roots, used for overdenture, transfers occlusal forces to the alveolar bone through the periodontal ligament and maintain alveolar ridge morphology.

In differentiating between occlusal forces, Pacer and Bowman discovered that the overdenture patient had more typical sensory function that is closer to natural teeth than a complete denture patients ${ }^{7}$. The periodontal receptors cyclic joint movements of mastication by influencing the muscles of mastication by their proprioceptive feedback mechanism. ${ }^{8}$ GIC was used because it had a chemical bond which attaches to the surface of dentin. Also, it contains fluoride which inhibits caries. ${ }^{9}$ Immediate overdenture is one of the best solution for denture fabrication without going through edentulousness. ${ }^{10}$
The case showed that overdenture can be used to prevents alveolar ridge bone absorption, stabilizes a denture, and makes the typical sensory function to be looked closer to natural teeth

\section{REFERENCES}

1. Kang,Sun Kang. Immediate fixed partial denture after toothextraction in patients with systemic diseases:A clinical report.J Adv Prosthodont. 2016;8(1);511-4.

2. Allegrini, S., Koening, B., Rivellino, M., Yoshimoto, M., Gedrange, T., Fanghaenel, J., and Lipski, M. Alveolar Ridge Sockets Preservation With Bone Grafting--Review. Annales Academiae Medicae Stetinensis. 2008;54(1);7081.

3. Kresnoadi, U., Rahayu, R. P..Stimulation of Osteoblast Activity by Induction of Aloevera and Xenograft Combination. Dental Journal. 2011;18(1);80-6.

4. Khana,Tulika S, Gurav, Sandeep Vivek, et al..ImmediateOverdenture.Journal of Contemporary Dentistry.2012;2(3);p.101-5.

5. Marinus.Treatment results with immediate overdenture : An evauation of 4,5 years. J Prosthet Dent.1996;76;p.153-7.

6. Pacer FJ, Bawman DC.Occlusal Force Discrimination by denture Patients. JProsthet Dent.1975;33;p.602-09.

7. Zarb GA, Bolender CL, Eckert SE, et al. Prosthdontics treatment for edentulous patients.CV.MosbyCo,St,Louis.2004;p.123-5.

8. Brewer AA, Morrow RM. Overdenture. $2^{\text {nd }} E d$. St Louis:The CV Mosby Co.1980;p3-11.

9. Darby, I., Chen, S., \& De Poi, R. Ridge Preservation: What Is It And When Should It Be Considered. Australian Dental Journal. 2008;53(1):11-21.

10. Lord JL, Teel S. Overdenture : patients selection, using coping, and evaluation. J Prosthet Dent. 1995; 32: 41-51. 